\title{
A Inefetividade dos Direitos Humanos e a Apropriação Liberal de seu Discurso A Influência das Corporações Transnacionais
}

\author{
Eduardo Baldissera Carvalho Salles \\ Mestre em Direito (Unochapecó). eduardo@carvalhosalles.com.br \\ Giovanni Olsson \\ Doutor em Direito (UFSC). Professor do PPG em Direito da Unochapecó. golsson71@gmail.com
}

Embora inexista um dissenso relevante a respeito da importância dos direitos humanos, estes enfrentam grandes restrições no que se refere a sua efetivação. Embora todos os teóricos, sejam eles universalistas ou relativistas, retoricamente defendam os valores humanitários, uma observação mais apurada logo constata que sua inexecutividade é um paradoxo contemporâneo que interessa a vários atores, sobretudo no plano internacional, onde tem ocorrido a proliferação de tratados de direitos fundamentais. Dessa forma, por meio de pesquisa bibliográfica pelo método dedutivo, este artigo objetiva abordar as vulnerabilidades dos direitos humanos na sociedade internacional, investigando a relação das corporações transnacionais com a aparente (in)eficácia desse discurso. Para tanto, inicialmente apresenta-se um levantamento histórico dos direitos humanos, tratando, dentre outros itens, sobre a evolução dos fundamentos legitimadores jusnaturais e positivistas. Em seguimento, afirma-se a ocorrência de uma apropriação ideológica liberal, a qual impacta na falta de concretização do discurso político no campo humanitário. Por fim, mostra-se que as corporações transnacionais desempenham papel destacado no cenário político internacional, cujas ações econômicas e comerciais influenciam a própria eficácia dos direitos humanos.

Palavras-chave: Direitos humanos. Discurso político. Corporações transnacionais.

THE INEFFECTIVENESS OF HUMAN RIGHTS AND THE LIBERAL APPROPRIATION OF HIS DISCOURSE: THE INFLUENCE OF TRANSNATIONAL CORPORATIONS

\section{ABSTRACT}

Although there is no significant dissent regarding the importance of human rights, they face great restrictions as regards their implementation. In spite of the fact all theorists, be they universalists or relativists, rhetorically defend humanitarian values, a closer observation promptly shows that their non-existence is a contemporary paradox that interests several actors, especially at the international level where there has been a proliferation of fundamental rights treaties. Thus, through a deductive method, the article aims to address the vulnerabilities of human rights in international society, investigating the relationship of transnational corporations with the apparent (in) efficacy of this discourse. For this, the historicity of human rights is first presented, dealing, among other things, with the evolution of legitimating foundations jusnaturalists and positivists. Later, it affirms the occurrence of a liberal ideological appropriation, which impacts on the lack of concretization of the political discourse in the humanitarian field. Finally, it is shown that transnational corporations play a prominent role in the international political scene, whose economic and commercial actions influence the very efficacy of human rights.

Keywords: Human rights. Political discourse. Transnational corporations.

SUMÁRIO

1 Introdução. 2 Desenvolvimento. 2.1 Elementos Históricos do Discurso dos Direitos Humanos. 2.2 Vulnerabilidades do Discurso dos Direitos Humanos. 2.3 Os Novos Atores: a influência das corporações transnacionais. 3 Conclusão. 4 Referências. 


\section{Introdução}

O debate acerca dos direitos humanos transcende as cátedras universitárias e foi abraçado pela maior parte da sociedade global. A expressão recebe a atenção da ciência jurídica ao mesmo tempo em que circula no vocabulário das pessoas comuns. Chama a atenção, entretanto, que os alicerces que legitimam o discurso são distintos, causando a impressão de que os direitos humanos da academia são diferentes daqueles que circulam na boca da sociedade.

Será que essa onipresença dos direitos humanos resulta em ações qualificadas e quantificadas que tendem a aumentar a proteção dos bens jurídicos tutelados, ou a retórica envolvendo esse discurso somente abstrai do conceito seus elementos aparentes, havendo uma mutação valorativa pelos atores que permeiam a sociedade global? Com o objetivo geral de esclarecer essa questão e, ainda, problematizar a influência das corporações transnacionais na efetivação dos direitos humanos, desenvolve-se o presente trabalho. Especificadamente, objetiva-se: (a) entender o pensamento político responsável pelo surgimento dos direitos humanos; (b) estudar a natureza das dificuldades em se instituir os direitos humanos; (c) verificar de que maneira as corporações transnacionais interagem com os direitos humanos, tanto influenciando-os quanto condicionando o seu discurso no âmbito global.

Para tanto, delinear-se-á uma breve história dos direitos humanos a fim de apontar os fundamentos que contribuíram para sua ascensão e consolidação com o advento do liberalismo político moderno, perpassando tanto a diferença entre a legitimação natural e positivista quanto sua relevância no âmbito da sociedade contemporânea.

Na sequência, explicitar-se-ão as vulnerabilidades do discurso dos direitos humanos, evidenciando a sua restrição estatocêntrica, sua apropriação pela ideologia liberal e as insuficiências da perspectiva tradicional para sua concretização.

Por fim, analisar-se-á a ascensão dos atores não estatais, notadamente das corporações transnacionais, e como esses novos protagonistas do cenário internacional influenciam e condicionam o próprio discurso dos direitos humanos. Na sequência, apresentar-se-ão brevemente as propostas e críticas dos Princípios do Pacto Global da ONU, os quais surgiram com a intenção de aproximar a prática das corporações transnacionais aos valores dos direitos humanos, minorando os custos humanos causados em virtude de suas atividades.

Assim, por meio de pesquisa bibliográfica pelo método dedutivo adota-se como hipótese inicial que o discurso dos direitos humanos é apropriado pela racionalidade liberal, e apenas uma leitura crítica aliada a uma análise pragmática do cenário político global é suficiente para (re)construir ferramentas eficientes para proteger os direitos humanos, deixando de lado alternativas meramente discursivas ou sem coercibilidade.

\section{Desenvolvimento}

Embora tenha havido um aumento significativo no número de instrumentos jurídicos internacionais que objetivam dar proteção humanitária além das fronteiras estatais, a observação de sua prática traz à luz um paradoxo provocativo. 


\section{Humanos e}

Democracia

Inexiste uma discordância factível envolvendo os direitos humanos, porquanto ninguém se opõe seriamente a tais valores. O principal entrave ocorre porque, ainda que todos os atores internacionais supostamente defendam os direitos humanos, estes nunca se concretizam plenamente, tanto em extensão quanto em profundidade.

Aparentemente, os direitos humanos não se efetivam em extensão porque grandes espaços do globo são ocupados por pessoas que não dispõem de condições materiais para uma sobrevivência digna - alimentação, habitação, educação e saúde, por exemplo - o que impossibilita reconhecer "parâmetros mínimos para algum referencial ético em termos de dignidade". Nesse contexto de extrema carência, é evidenciado que "a distinção entre seres humanos e animais, em alguns casos, pode ser puramente antropomórfica e genética" (OLSSON, 2004, p. 2).

Os direitos humanos também não se concretizam em profundidade porquanto há diferentes graus de efetivação desses direitos. É possível, sem esforço, assinalar que as pessoas residentes em áreas desenvolvidas do mundo dispõem de mais alimentação para satisfação de suas necessidades do que aquelas de locais subdesenvolvidos. Da mesma forma, recentes indicadores econômicos evidenciam que os níveis de desigualdade e exclusão estão em frenético crescimento, especialmente no denominado Terceiro Mundo (OLSSON, 2004, p. 3), bem como vários estudos apontam que $82 \%$ de toda a riqueza mundial gerada entre setembro de 2016 a setembro de 2017 ficou nas mãos de apenas 1\% da população mais rica (OXFAM, 2018).

$\mathrm{Na}$ hipótese aqui em discussão, não interessa descobrir exatamente as razões que provocam este fenômeno, mas sim compreender porque, embora haja uma confluência discursiva envolvendo os direitos humanos, a humanidade está a cada dia menos "humana".

Arrisca-se afirmar que esse paradoxo sinaliza a existência de incompatibilidades na tessitura social, as quais envolvem, principalmente, uma apropriação ideológica do discurso dos direitos humanos, bem como uma teoria que se mostra insuficiente e incapaz de apresentar soluções às demandas concretas da sociedade.

Para explicitar tais fatores, no entanto, é impositivo que se delineie a evolução histórica dos direitos humanos como categoria conceitual, o que será desenvolvido no próximo tópico do presente estudo.

\subsection{Elementos Históricos do Discurso dos Direitos Humanos}

A inspiração para o surgimento dos direitos humanos ocorreu no âmbito do jusnaturalismo. Sua proposta era de que tais valores constituiriam um mínimo moral intrínseco aos indivíduos, oponível a todos, e, em especial, ao Estado.

Tal corrente do pensamento indicava a existência de um arcabouço de valores morais que deveriam ser incorporados e refletidos pelo Direito. Seus críticos, por outra via, questionavam seu fundamento teórico, arguindo que a estipulação de valores fundamentais universais decorrentes da natureza humana, ou de uma providência divina, só poderia ocorrer em um âmbito meramente ideacional.

Mesmo assim, as indicações jusnaturalistas tiveram importante repercussão no que se refere à tentativa de efetivação de instrumentos jurídicos que assegurassem um mínimo ético aplicável a todas as sociedades. 
Nesse contexto surgiu o movimento racional-positivista, que, por sua vez, referia que os seres humanos eram capazes de, por meio da razão, entender e transformar o mundo conforme as suas próprias vontades.

A corrente racional-iluminista instituiu, desse modo, as premissas para o discurso da modernidade, cujas máximas de liberdade, igualdade e fraternidade ainda repercutem na maior parte das instituições seculares.

No século 16, graças a uma burocracia competente e à ascensão da burguesia como classe dominante, o Estado (do latim status = estar firme) consolidou-se como um grande paradigma, responsável por proteger o homem das intempéries do estado de natureza e firmar instrumentos garantidores de que a liberdade alienada no pacto não se voltasse aos seus próprios "criadores". Por outro lado, esse aparato racional-burocrático aliou o ente político com o jurídico, de modo que passou a exercer, com exclusividade, a regulação social, impedindo a ocorrência de justiça privada ou a policentricidade normativa, fenômenos típicos da Idade Média.

Crítico da teoria moderna de maximização instrumental e denunciante das "jaulas de ferro" que envolvem o homem na sociedade capitalista, Weber argumenta que o Estado, ao deter o monopólio da coação legítima, transferiu para o Estado-nação o privilégio da produção de normas regulatórias. Para ele, os liberais modernos, com temor da tirania absolutista, dotaram o Leviatã de um sistema de freios e contrapesos construído justamente para garantir direitos, controlar as ações e empoderar a sociedade civil.

Para Weber, o Estado não é apenas de Direito, no sentido de agregar o discurso jurídico as suas instituições, mas também liberal, porque possui atuação limitada pela vontade dos indivíduos, mediante mecanismos institucionais e constitucionais de controle. Nesse contexto, "as ideias de separação de poderes, de controle externo de órgãos, de tipicidade e anterioridade penal, de direito adquirido, de ato jurídico perfeito, de inércia jurisdicional, de mandatos temporários a legisladores" são, juntamente com o conceito de direito fundamental, expressões deste propósito garantidor de direitos (OLSSON, 2004, p. 5).

Tem-se que, no conceito liberal, o Estado é "limitado" pelo Direito. Tanto para Locke como para Montesquieu, as normas são o caminho indispensável para a liberdade. Por outro lado, Pietro Costa refere que "aquilo que, para Montesquieu, impede o despotismo - a degeneração de um bom regime político - é feliz conúbio entre liberdade e lei. O indivíduo é livre enquanto age nos trilhos da lei e esta, por sua vez, é o único instrumento capaz de protegê-lo do arbítrio" (COSTA, 2006, p. 103).

Por isso, os princípios ideológicos do Estado, que instituem, fundam, regulam e legitimam suas ações, passaram a ser positivados em documentos de difícil alteração legislativa e de alta relevância hierárquica: esse é o nascedouro teórico da Constituição.

Não se pretende tratar de sua origem, importância, extensão ou conformação, mas evidenciar que a estrutura político-jurídica da sociedade contemporânea está lastreada de forma preponderante em leis fundamentais escritas, as quais, salvo raras exceções, geralmente protegem valores como a vida, a liberdade, a dignidade, a igualdade e a segurança. 


\section{Democracia}

Os direitos humanos, até então definidos como metafísicos e irracionais, foram sistematizados e incorporados às estruturas das nações pelas Constituições, de modo que passaram a constituir um novo arcabouço nominado de direitos fundamentais.

Tratar dessa passagem dos direitos humanos, do natural ao positivismo, embora pareça pouco relevante em uma açodada análise, é primordial para a adequada compreensão de quanto o seu discurso contemporâneo é centrado no Estado. Esse fenômeno causa dificuldades para a efetivação dos direitos humanos no cenário internacional, especialmente porque as nações detêm soberania suficiente para decidir se farão uma maior ou menor incorporação ao ordenamento interno.

Exemplificativamente, pode-se referir que se um Estado reconhecer maior número de direitos fundamentais do que outro, há uma lógica suposição de que um seja melhor que o outro, estimulando a imigração. No âmbito da política internacional, também é possível mencionar que, se uma ordem jurídica nacional abarcar níveis mais elevados de direitos humanos, esse passa a constituir um novo referencial, instigando o debate e a alteração de legislações estrangeiras, especialmente se essa nação for uma potência socioeconômica que exerça influência econômica ou cultural sobre as demais.

Essa interpretação ainda pode desaguar na consolidação do pensamento de que uma nação que dê prevalência aos direitos humanos deve ser reconhecida como superior às demais, e, por isto, legítima para portar o estandarte dos valores humanitários sobre terras "bárbaras", irradiando o seu padrão político, jurídico, cultural, sociológico e, especialmente, econômico.

Por isso, uma observação atenta dos principais instrumentos históricos envolvendo direitos humanos revela que eles não são mais do que produtos de um fenômeno de homogeneização normativa estatocêntrica. A Declaração Universal dos Direitos Humanos (1948), de teor reconhecidamente ocidental, foi editada durante o rescaldo e sobre os escombros da Segunda Guerra Mundial, constituindo um exemplo que salta aos olhos.

Dessa forma, e embora haja uma harmonia discursiva, com dezenas de instrumentos internacionais e Organizações Não Governamentais envolvidas na efetivação desses valores, as indagações preliminares continuam latentes: Por que os direitos humanos não são respeitados na mesma extensão da sua discursividade e normatização presentes?

Como a seguir demonstrar-se-á, existem diversas vulnerabilidades no tema.

\subsection{Vulnerabilidades do Discurso dos Direitos Humanos}

É incontroverso que a ideologia desempenha função relevante na discussão envolvendo os direitos humanos. Algumas necessidades humanas, protegidas pela locução humanitária - saúde, alimentação, moradia, por exemplo - não podem ser instituídas sem que se faça um debate envolvendo, além da esfera jurídica, os âmbitos social, econômico e político, no entanto a abordagem dessas necessidades humanas como se fossem celeumas meramente jurídicas, utilizando-se da máscara dos direitos humanos, pode configurar uma apropriação liberal do discurso. 
É preciso destacar que essa apropriação não é de todo perniciosa. Seu lado positivo reside no fato de que, por fundar-se na limitação do Estado, há uma parcial identificação e promoção dos direitos humanos. Esse sistema de ideias, no entanto, distorce a prática, adaptando o discurso e tornando-o incoerente. Sistematicamente, essa deformação da essência do debate é causada por três tipos diferentes de apropriação: pela forma, pelo conteúdo e pelo procedimento (OLSSON, 2004, p. 8-16).

A forma (juridicizada) refere-se ao método de veiculação da questão dos direitos humanos. Em que pese parecer incontroverso que os direitos humanos reproduzam-se por normas, a afirmação não deve ser tomada por irrefragável. Isso porque o método político e social de difusão desses valores foi apropriado por uma forma jurídica, de modo que, na sociedade contemporânea, quase não se discutem métodos assecuratórios da vida e da saúde, por exemplo, fora do Direito.

Evidentemente que o Direito é um instrumento muito importante de regulação social, no entanto não é o único. Seu principal defeito é a incapacidade de agregar a sua estrutura todas as necessidades do discurso dos direitos humanos. Isso, contudo, não se dá por acaso, tratando-se de um dos subprodutos da modernidade, que converteu o debate das necessidades humanas em contendas meramente jurídicas. $\mathrm{E}$, ao afirmar isso, não se pretende defender que este método seja inadequado, mas, ao contrário, objetiva-se evidenciar que a excessiva racionalização instrumental jurídica desfoca o cerne do problema.

Ao monopolizar a regulação social no Direito, o Estado-nação afastou o conceito de valores humanos relacionado à satisfação de necessidades, estruturando tal ideário com conteúdo (jurídico) e espaço (nacional) limitados. Nesse contexto, as necessidades humanas (saúde, dignidade, alimentação, etc.) acabam sendo restritas e circunscritas àquelas garantidas pela ordem jurídica nacional, independentemente dos valores expressos em outras fontes (OLSSON, 2004, p. 9).

Exemplificativamente, se confrontarmos os direitos humanos reconhecidos na França e na Síria, por exemplo, facilmente concluiremos que o país europeu estruturou um sistema mais extenso e complexo de direitos e garantias fundamentais. Daí que, embora o ser humano sírio seja tão "humano" quanto o francês, este, na prática do mundo da vida, vale mais do que aquele. As necessidades das pessoas são iguais, mas os sistemas jurídicos nacionais tratam como se não fossem, o que, logicamente, viola as próprias premissas dos direitos humanos e seu próprio discurso histórico internacional.

O reflexo mais desastroso dessa limitação é que, como fruto da alienação liberal, não se discutem as causas sociais, políticas e econômicas que impedem a adequada satisfação das necessidades humanas, mas apenas as jurídicas, as quais são incapazes de apresentar soluções à questão.

No que se refere ao segundo tipo de apropriação, que ocorre pelo conteúdo (limitado), este é facilmente identificável no discurso liberal que, deliberada e convenientemente, defende somente determinados aspectos dos direitos humanos. A ideologia que envolve os princípios da igualdade, liberdade e fraternidade fala por si. 


\section{Humanos e}

Democracia

Exemplo disso é que o direito de igualdade é racionalizado apenas sob a égide formal, como se o fato de brancos e negros pertencerem à espécie humana dissolvesse por si mesmo as diferenças materiais e de acesso a bens da vida entre eles. De mesmo modo, em que pese o fato de que todos os povos do mundo serem formalmente iguais, existem entraves políticos, jurídicos e sociais que impedem a imigração de pessoas às nações de Primeiro Mundo. Para a construção de um discurso humanitário coerente é inadmissível que a igualdade seja considerada somente no plano ideal ou retórico.

A liberdade, por sua vez, limita-se à dimensão negativa, de inexistência de obstáculos estatais (ALEXY, 1997, p. 340), a qual é reconhecidamente incapaz de dar eficácia plena à liberdade como valor humano, porquanto, embora o Estado não impeça os indivíduos de comprar alimentos, nem todos possuem recursos suficientes para tanto. Desse modo, "a liberdade acaba se resumindo a uma espécie de liberdade negativa universal de não ser impedido de beber Coca-Cola, ainda que não se tenha a liberdade positiva para ter meios de adquiri-la ou mesmo de ter moradia e saúde" (OLSSON, 2004, p. 11). Por esta razão, apesar de a liberdade ser um dos direitos mais difundidos pelo globo, é justamente aquele que menos se materializa, de modo que, para a superação desse paradigma, a sociedade internacional deve adotar instrumentos que garantam a liberdade também sob seu viés negativo.

Quanto à fraternidade liberal, seu discurso é marcantemente incoerente. Exemplo é o fornecimento de alimentos ou medicamentos pela sociedade durante algum extraordinário episódio de calamidade. Enquanto as doações constituem um anódino efêmero, que cessa ao apagar das luzes da mídia, a sociedade não se importa com as verdadeiras razões do problema (fome, desemprego, desigualdade social, etc., por exemplo), porquanto, para fazê-lo, teria de tomar posições desinteressantes à própria estrutura capitalista, a qual alimenta medievalismos sociais e econômicos. Esse discurso também é identificável nas corporações transnacionais que, de um lado assumem uma "responsabilidade social", e de outro, violam direitos humanos ecológicos e da dignidade do trabalho, em escabrosa escala.

Cabe anotar, por fim, que a terceira apropriação se dá pelo procedimento (seletivo), uma vez que a ideologia liberal seleciona as hipóteses de incidência dos direitos humanos, os quais, ao invés de se universalizarem, acabam retidos e limitados a casos esporádicos e que convêm aos interesses do sistema.

Nesse argumento, os direitos humanos são facilmente utilizados como instrumento de política internacional para angariar recursos contra um determinado inimigo (pretensamente ditatorial ou intolerante religioso) que monopoliza muitos recursos naturais (ouro, gás ou petróleo), do que para solucionar a carência de alimentos, moradia, saúde e dignidade de parcelas territoriais que não abrigam qualquer bem econômico valioso. Esse discurso é dificilmente oposto a nações desenvolvidas que, apesar de alegarem defesa dos valores humanitários, praticam e consentem com a tortura de presos, por exemplo. Aparentemente, "o discurso neoliberal de direitos humanos tem sua eficácia em relação diretamente proporcional com a força econômica (e militar) de quem o sustenta" (OLSSON, 2004, p. 12).

Cabe destacar que o intento não é discutir o mérito ou a validade do sistema cultural e ideológico ocidental perante os demais, mas evidenciar que a apropriação liberal dos direitos humanos, que é causa relevante de sua ineficácia, ocorre por decisão deliberada do sistema econômico, transvestindo-se de insuficiência teórica. 
Não por acaso a globalização neoliberal agravou esses efeitos, fazendo com que surgissem novos atores no cenário internacional, os quais têm condicionado o debate dos direitos humanos conforme os interesses do mercado.

\subsection{Os Novos Atores: a influência das corporações transnacionais}

Nas artes cênicas o ator é responsável por atuar, interpretar e representar uma ação dramática previamente definida. Ao ator geralmente é franqueado o uso de todos os recursos corporais, especialmente a voz e as emoções, com o objetivo de envolver e transmitir ao maior número de espectadores as ideias inicialmente propostas. Considerando a similitude da política internacional com as atribuições dos envolvidos na dramaturgia, seus termos foram apropriados pelas Relações Internacionais para nominar os agentes, públicos ou privados, que influenciam, condicionam e interagem na sociedade internacional.

Entre as características elementares para definir se um agente é um ator internacional destaca-se a habilidade, capacidade, autonomia e influência dele em convencer a comunidade global a tomar decisões envolvendo temas econômicos, militares, políticos, sociais e religiosos, entre outros.

Nesse sentido, em que pese o fato de dois atores poderem desenvolver as mesmas ações, estas podem causar efeitos distintos, porque o cenário sofre variações conforme o grau de autonomia, habilidade e capacidade de seus protagonistas. Tais interações estão imbricadas no próprio conceito de ator internacional, que, segundo Esther Barbé, "é aquela unidade do sistema internacional (entidade, grupo, indivíduo) que tem habilidade para mobilizar recursos que lhe permitem alcançar seus objetivos e capacidade para exercer influência sobre outros atores do sistema e que goza de certa autonomia" (BARBÉ, 1993, p. 117).

Há diversos fatores que interferem na autonomia dos atores internacionais, de modo que os métodos de operação podem se modificar para atender ao cenário ou aos interesses dos envolvidos. Odete Maria de Oliveira reproduz a categorização de Pereira Castañares com cinco fatores determinantes que influem no grau de protagonismo dos atores: geográfico, demográfico, econômico, militar e de segurança e tecnológico (OLIVEIRA, 2014, p. 68-96).

Embora haja uma diversidade de categorizações envolvendo o tema, Oliveira indica três espécies que, abarcadas sob um "parâmetro eclético", englobam todos os fluxos da sociedade internacional contemporânea. São "os denominados atores tradicionais, os novos atores e os atores emergentes" (2014, p. 100).

Na espécie "atores tradicionais", encontram-se os Estados nacionais e as organizações internacionais intergovernamentais, estas últimas porque são fruto de tratados envolvendo os primeiros.

No que se refere aos "novos atores", estes são as organizações internacionais não governamentais e as corporações transnacionais, as quais detêm, em um contexto de globalização, a maior parte dos recursos materiais e ideacionais do mundo. 


\section{Humanos e}

Democracia

Por outro lado, os "atores emergentes" podem ser caracterizados como líquidos e voláteis, visto que não possuem estrutura rígida de direção, cujos exemplos mais notáveis são os movimentos sociais, a mídia, o crime organizado e o terrorismo. Estes últimos não possuem área de abrangência definida, uma vez que atuam em diversas relações e meios, o que constitui o principal atributo desta espécie.

Assim, pode-se referir que a institucionalidade, a burocracia, a direção privativamente privada e o grande impacto global são marcos distintivos da espécie dos "novos atores". No âmbito do presente estudo, porém, a atenção volta-se apenas para o papel das corporações na instituição dos direitos humanos.

Algumas corporações transnacionais, possuidoras de gigantesco poder econômico maior que a soma de dezenas de nações - são capazes de influenciar e condicionar os outros atores para além das fronteiras de seus Estados.

Como resultado da globalização neoliberal, que dotou a racionalidade econômica de instrumentos da telemática, as corporações transnacionais operam em interligação viva com o mercado, a produção e a gestão dos negócios. Não possuem capital ou direção determinados, mas, ao ramificá-los pelo globo, elidem tributos e faturam mais que a soma do Produto Interno Bruto de diversos países somados (SALLES, 2018, p. 51).

As práticas de governança econômica dessas corporações transnacionais fogem às mãos dos Estados nacionais, porquanto o gigantesco poder econômico e os efeitos gerados por estas nos indicadores de emprego e renda submetem os governos à vontade corporativa, independentemente de eventual (i)legitimidade internacional ou (des)respeito a valores humanitários (SALLES, 2018, p. 77).

Aí está o centro da questão. A globalização fez com que o exercício de poder global independa de governos, assemelhando a contemporaneidade ao modelo medieval, até então apinhado de governanças setoriais (FRIEDRICHS, 2001, p. 483-491). Com a competição por supremacia econômica, os atores internacionais submetem-se somente ao capital, e não aos direitos humanos.

O efeito disso é nefasto. Como inexistem instâncias sociais, políticas e jurídicas capazes de fiscalizar, orientar e controlar as corporações transnacionais, as quais possuem faturamento superior ao Produto Interno Bruto de dezenas de países, suas práticas não podem ser referenciadas territorialmente. Assim, as recorrentes violações a direitos fundamentais, notadamente sociais e ambientais (desemprego e vazamentos de petróleo, por exemplo), não são passíveis de controle e responsabilização eficientes.

Mais do que isso, fica fácil concluir que a dependência econômica desses atores é tamanha que mesmo os tratados de precaução e punição a violações de direitos humanos são propositadamente deficientes, faltando-Ihes mecanismos capazes de aplicar sanções com efetividade no âmbito global, de modo que eles se transformam em cartas de boas intenções, cujas reprimendas são apenas morais ou retóricas e não obrigam o infrator.

Esse problema ocorre, segundo Galtung, porque "o Estado pode proteger, mesmo garantir, a satisfação de necessidades e pode impedir, obstruir e mesmo destruir quaisquer hipóteses de satisfação de necessidades" (1994, p. 103). Observa ele que "o problema não se resolve fazendo do Estado o recipiente de um número cada vez maior de normas cuja im- 
plementação levaria a um nível crescente de satisfação de algumas necessidades de base, adicionando a isto a institucionalização através dos vários mecanismos discutidos acima" ( $p$. 106), porque existe uma "dialética cruel" operativa. O Estado (como meio) pode alterar as necessidades dos direitos humanos (como fins) não apenas pela sua apropriação abusiva, mas também pelo seu próprio uso correto em si mesmo.

Isso porque "é possível, como no Estado previdência moderno, ganhar em sobrevivência, bem-estar e liberdade, enquanto ao mesmo tempo se perde em identidade, adquirindo os três à custa da alienação" (GALTUNG, 1994, p. 106). Desse modo, a perspectiva instrumental não é capaz de suprir as necessidades humanas, especialmente no tocante à identidade, porque existe certa dificuldade de identificação dos garantidores de direitos humanos, porquanto "quase todos os direitos individuais de ordem civil, política, econômica, social e cultural são operacionalmente reclamáveis, por parte do indivíduo, à administração e aos demais poderes constituídos em seu Estado patrial", enquanto que, ante a dificuldade de se apurar a responsabilidade por sua efetivação ou violação, a situação fica mais complexa quando se trata "saber de quem exigiremos que garanta nosso direito ao desenvolvimento, à paz ou ao meio ambiente" (REZEK, 1998, p. 223).

Um exemplo disso é apontado por Galtung, que indaga: "Se a estrutura produz fome, como a estrutura internacional do mercado agrícola pode ser acusada de desrespeitar os direitos humanos?" (1994, p. 108). Quem seria o "réu" nessa relação? Os Estados que possuem produção agrícola? As corporações transnacionais de biotecnologia ou de distribuição e comercialização de alimentos? As organizações internacionais de fomento agrícola e planejamento? Os produtores individuais?

É uma solução difícil de ser apurada. Todos esses atores (Estados, corporações transnacionais e indivíduos produtores) compõem um sistema no qual cada um desempenha papel específico, entretanto eles são peças de uma engrenagem bem mais complexa, que constitui uma operatividade própria de produção de bens agrícolas. Existe, portanto, uma estrutura complexa de produção de alimentos como um todo, regida pela racionalidade liberal, cujo objeto inicial não é erradicar a fome da população mundial (porque, se assim o fosse, já poderia tê-lo feito há muito tempo, inclusive pelos colossais excedentes agrícolas), mas sim apenas daqueles que podem pagar por isso, isto é, atender à margem de lucro de um mercado próspero que se alimenta da fome alheia, o agribusiness.

É indispensável reconhecer, sobretudo, que não há apenas atores "bons" ou "maus", mas fundamentalmente "estruturas erradas", como afirma Galtung, que devem ser mudadas. Nesse sentido, articula ele: "A estrutura, não sendo uma pessoa jurídica, não pode ser dada como culpada, só como errada. Mas aqueles que mantêm a estrutura através das suas acções ou que não as desmantelam através de sua inacção podem ser dados como culpados" (GALTUNG, 1994, p. 219).

É claro que isso ultrapassa o Direito e ingressa na política (estrutura envolve uma relação de poder) e na cultura (estrutura mantém-se e reproduz-se também por ideologia difundida) e também na economia (estrutura atende a interesses do mercado, pela racionalidade econômica colonizadora das outras instâncias). A afirmação faz com que se verifique que a complexidade da vida contemporânea, especialmente quanto aos direitos humanos, não comporta apreciação puramente jurídica e apartada de seus fundamentos teóricos. 


\section{Humanos e \\ Democracia}

Nesse sentido, John Gerard Ruggie, um dos primeiros estudiosos a se debruçar sobre o tema dos direitos humanos no contexto das corporações transnacionais, vem examinando várias questões de abusos desses direitos e propondo soluções principiológicas e proteções regulatórias para mitigar os custos humanos causados pela maximização desenfreada do lucro da sociedade neoliberal (RUGGIE, 2013, p. XXIV).

Segundo Ruggie, deve-se encontrar um método de responsabilizar as corporações transnacionais, ainda que elas não sejam reguladas globalmente e operem de maneira capilar, com cada unidade sujeitando-se à jurisdição do Estado no qual opera. Isso porque, mesmo onde existem leis nacionais proibindo determinadas condutas violadoras dos direitos humanos, tais normas nem sempre são respeitadas, seja porque falta aos Estados capacidade de coerção, porque temem causar fuga de investimentos e capitais ou ainda porque seus líderes subordinam-se a interesses privados (2013, p. XVI).

Ao desenvolver sua proposta Ruggie sugere a adoção do "Princípio do Pragmatismo", cujo estabelecimento no contexto global dependeria da adesão voluntária dos representantes políticos, dos organismos internacionais e das corporações transnacionais ao compromisso "inabalável" de fortalecer a promoção e a proteção dos direitos humanos relacionados aos negócios (2013, p. XLII-XLIII). Nesse viés, e em verdade, Ruggie não oferece nenhuma abordagem inovadora para os problemas narrados, insistindo na solução regulatória e na adesão espontânea dos atores na defesa pragmática dos direitos humanos, o que, na prática, significa esperar de corporações e da sua racionalidade econômica puramente instrumental uma espécie de ethos coletivo um tanto quanto improvável.

Em sua obra, de qualquer forma, Ruggie ainda elenca 31 princípios que devem ser observados por governos e corporações transnacionais. Em 2 tais princípios foram endossados pelo Conselho de Direitos Humanos da ONU e foram a base do denominado "Pacto Global da ONU", no qual John Ruggie desempenhou um papel crucial na criação e construção. O principal argumento do Pacto Global é a mudança da postura ética das corporações transnacionais em suas ações comerciais, devendo elas se preocuparem com os custos humanos e, assim, garantirem a continuidade da globalização. A efetividade do instrumento ficaria a cargo da visibilidade, do alcance global e do poder dos stakeholders, que constrangeriam os negócios, suscitando no âmbito global o descumprimento dos princípios.

Inexistem, entretanto, mecanismos de monitoramento ou avaliação sobre a efetivação dos princípios pelos signatários. Consequentemente, após a adesão de "7.000 empresas e redes nacionais em mais de 50 países" (RUGGIE, 2013, p. XXVII), inexistem evidências materiais demonstrando que tipo de progresso essas corporações alcançaram ao aderir ao documento e se as suas condutas em relação aos direitos humanos realmente têm sido melhores que as das corporações não signatárias.

Diante, portanto, das dificuldades em se apurar o sucesso da solução sugerida por Ruggie, e da inexistência de ferramentas de revisão de desempenho e transparência em sua execução, os críticos do Pacto Global das Nações Unidas depreciam-no por se tratar de retórica vazia e esforço inútil das agências internacionais. Nesse contexto, argumentam que a iniciativa constitui apenas uma forma de limpar a imagem das corporações mediante o uso dos valo- 
res da ONU como plataforma de propaganda. Além disso, os signatários do Pacto Global são simplesmente "encorajados" a seguir os princípios, existindo a ideia de "práticas melhores", as quais não constituem condutas obrigatórias a serem adotadas (CENTRE..., 2007).

Apesar de o autor descrever situações nas quais agências internacionais, autoridades nacionais e Organizações Não Governamentais lograram êxito em convencer as corporações transnacionais a minorarem os danos à humanidade causados por determinados empreendimentos industriais em localidades pobres (como a mineração de ouro ou a fabricação de vestuário), tais exemplos não são abrangentes ou representativos e escapam da questão principal, que é a apropriação do discurso humanitário por uma lógica neoliberal.

Os danos suportados por comunidades pobres expostas por décadas à poluição com metais pesados, por exemplo, não são facilmente revertidos com medidas paliativas, superficiais ou caritativas, as quais servem apenas como certo "desencargo de consciência". A solução, por evidente, é complexa, mas exigiria reformulações estruturais no sistema econômico, porque, afinal, a sociedade neoliberal possui uma racionalidade intrínseca (DARDOT; LAVAL, 2016).

\section{Conclusão}

O presente trabalho, cujo principal objetivo era entender a relação entre o papel das corporações transnacionais e a concretização dos direitos humanos, dedicou-se a, inicialmente, elaborar uma concisa historicidade dos direitos humanos, tratando dos fundamentos por trás de sua ascensão e consolidação como discurso hegemônico na sociedade contemporânea.

Após, apuraram-se as vulnerabilidades dos direitos humanos na atual conformação global, notadamente sua apropriação liberal e a incapacidade dessa doutrina de impor eficácia a ações colidentes com a ideologia econômica vigente. Nesse ponto importante assinalar que foram abordadas detalhadamente três dimensões de apropriações desse discurso: pela forma (juridicizada), pelo conteúdo (limitado) e pelo procedimento (seletivo).

No terceiro aspecto tratou-se dos atores internacionais, com a ascensão e consolidação destes, notadamente das corporações transnacionais, e como esses novos protagonistas influem e condicionam o próprio discurso dos direitos humanos além das fronteiras nacionais e sob os efeitos da globalização neoliberal. Nesse item ainda se referiu que inexistem atores "bons" ou "ruins", mas somente "estruturas erradas", as quais não podem ser compreendidas e enfrentadas por uma abordagem meramente jurídica.

Também expôs-se a proposta de Ruggie para minoração dos custos humanos causados pelas ações das corporações transnacionais no cenário global, e as críticas mais correntes apresentadas em desfavor da efetividade dos Princípios do Pacto Global da ONU.

Confirmou-se a hipótese inicial de que o discurso dos direitos humanos é apropriado pela racionalidade liberal. Assim, apenas a crítica aos direitos humanos conjugada a uma análise pragmática da política internacional será capaz de (re)construir mecanismos eficientes de proteção dos seres humanos e autêntica promoção da dignidade em toda a extensão do globo, desconsiderando proposições vazias e meramente ideacionais. 


\section{Humanos \\ Democracia}

\section{Referências}

ALEXY, Robert. Teoría de los derechos fundamentales. Trad. Ernesto Garzón Valdés. Madrid: Centro de Estudios Constitucionales, 1997.607p.

ARRUDA JR., Edmundo Lima de; GONÇALVES, Marcus Fabiano. Fundamentação ética e hermenêutica: alternativas para o direito. Florianópolis: Cesusc, 2002. 337p.

BARBÉ, Esther. Relaciones internacionales. Madrid: Tecnos, 2007.

CENTRE FOR APLIED STUDIES FOR INTERNATIONAL NEGOTIATIONS (CASSIN). UN and Business: Where do we stand? Programme on Global Issues \& Civil Society. Geneva: Report, 2007.

CHESNAIS, François. A mundialização do capital. Trad. Silvana Finzi Foá. São Paulo: Xamã, 1996. 335p.

COSTA, Pietro; ZOLO, Danilo (Orgs.). O Estado de Direito: história, teoria, crítica. São Paulo: Martins Fontes, 2006. DARDOT, Pierre; LAVAL, Christian. A nova razão do mundo: ensaio sobre a sociedade neoliberal. Trad. Mariana Echalar. 1. ed. São Paulo: Boitempo, 2016.

FRIEDRICHS, Jorg. The meaning of new medievalism. European Journal of International Relations, London, v. 7, p. 475-502, 2001.

GALTUNG, Johan. Direitos humanos: uma nova perspectiva. Trad. Margarida Fernandes. Lisboa: Instituto Piaget, 1994. 252p.

OLIVEIRA, Odete M. Relações internacionais, direito e poder - cenários e protagonismos dos atores não estatais. ljuí: Ed. Unijuí, 2014. 432p. V. I.

OLSSON, Giovanni. O poder político no espaço global: o protagonismo dos atores estatais e não estatais. In: OLIVEIRA, Odete M. Relações internacionais, direito e poder - cenários e protagonismos dos atores não estatais. Ijuí: Ed. Unijuí, 2014. 432p. V. I.

A apropriação liberal do discurso dos direitos humanos e uma nova hermenêutica de superação. Revista do Tribunal Regional do Trabalho da 15a Região, 24. ed., 31p., 2004.

Poder político e sociedade internacional contemporânea: governança global com e sem governo e seus desafios e possibilidades. Ijuí: Ed. Unijuí, 2007. 552 p.

OXFAM. El 1\% más rico de la población mundial acaparó el 82\% de la riqueza generada el año pasado, mientras que la mitad más pobre no se benefició en absoluto. Disponível em: <https://oxf.am/2rpFhfS>. Acesso em: 9 jun. 2018.

PRONER, Carol. Os direitos humanos e seus paradoxos: análise do sistema americano de proteção. Porto Alegre: SAF, 2002. 247p.

REZEK, José Francisco. Direito internacional público: curso elementar. 7. ed. rev. São Paulo: Saraiva, 1998. 410p. RUGGIE, John G. Constructing the world polity: essays on international institutionalization. London: Routledge, 1998. 2013. 251p

Just Business: Multinational Corporations and Human Rights. Nova York: W. W. Norton \& Company, SALLES, Eduardo B. C. Corporações transnacionais: novos atores e novos poderes. Porto Alegre, RS: Editora Fi, 2018. 180p.

SEN, Amartya. Desenvolvimento como liberdade. Trad. Laura Teixeira Motta. São Paulo: Companhia das Letras, 2000. 409p.

TRINDADE, Antônio Augusto Cançado. A proteção internacional dos direitos humanos e o Brasil (1948-1997): as primeiras cinco décadas. 2. ed. Brasília: UnB, 2000. 214p.

WEBER, Max. Economia y sociedad. Trad. José Medina Echavarría et al. 2. ed. México: Fondo de Cultura Económica, 1998. 1.237p. 